\title{
AWAKENING CHARACTERISTICS AND RECOVERY OF COGNITIVE FUNCTION IN PATIENTS UNDERGOING SHORT SURGICAL PROCEDURES: COMPARISON BETWEEN DESFLURANE AND PROPOFOL
}

\author{
FERNAZ BASHA ${ }^{1}$, PARTHASARATHY $S^{2}$, ANTONY JOHN CHARLES ${ }^{2 *}{ }^{2}$, RAVISHANKAR ${ }^{2}$, HEMANTH KUMAR VR ${ }^{2}$ \\ ${ }^{1}$ Consultant Anaesthesiologist, Fathima Hospital, Arcot, Tamil Nadu, India. ${ }^{2}$ Department of Anaesthesiology, Mahatma Gandhi Medical College \\ and Research Institute, Sri Balaji Vidyapeeth Deemed to be University, Pillaiyarkuppam, Puducherry, India. Email: anjocharlie@gmail.com
}

Received: 12 August 2021, Revised and Accepted: 29 October 2021

ABSTRACT

Objectives: Early awakening and recovery of the cognitive function improves post-operative outcome and early discharge of the patients. Desflurane and Propofol offer rapid emergence from anesthesia. We compared the awakening and recovery of cognitive function between these two agents.

Methods: A total of 50 patients aged 30-60 years belonging to ASA 1 and 2 were studied. In both the groups baseline, Mini Mental State Examination (MMSE) score was recorded and were induced with Target controlled infusion (TCI) of Propofol to achieve plasma site concentration (Cp) of 6 mcg/ml. Group P continued with TCI Propofol Cp $3 \mathrm{mcg} \mathrm{ml}^{-1}$ and in group D, TCI was stopped and started Desflurane $6 \%$ end tidal concentration followed by Desflurane 3\%. Hemodynamic variables were noted and after stopping the agent, time to eye open, squeeze hands, removal of laryngeal mask airway, state name, and modified Aldrete score were noted. MMSE score was recorded 1, 6, and 24 h postoperatively.

Results: Awakening time was significantly shorter in duration in Desflurane group compared to Propofol. The mean time to eye open in the Propofol group was $10.41 \pm 2: 31 \mathrm{~min}$ and Desflurane group was $06.21 \pm 01.42 \mathrm{~min}\left({ }^{* * *} \mathrm{p}=0.000\right)$. There was an increase in the mean MMSE score postoperatively at $6 \mathrm{~h}$ and $24 \mathrm{~h}$ interval when compared to the baseline within the groups. However, there was no difference in recovery of cognitive function between the two groups.

Conclusion: The use of inhalational agent Desflurane provided shorter awakening time than intravenous Propofol in short surgical procedures but the recovery of cognitive function was comparable. There were no significant side effects.

Keywords: Desflurane, Propofol, Awakening, Recovery, Cognitive function.

(c) 2021 The Authors. Published by Innovare Academic Sciences Pvt Ltd. This is an open access article under the CC BY license (http://creativecommons.org/ licenses/by/4.0/) DOI: http://dx.doi.org/10.22159/ajpcr.2021v14i11.43089. Journal homepage: https://innovareacademics.in/journals/index.php/ajpcr

\section{INTRODUCTION}

Awakening of the patient is liberating the patient from the state of anesthesia when the requirement of anesthesia is no longer needed. It should be smooth, quick and must have only minimal residual effect to the patient. There is an increasing trend toward day care surgeries in recent times [1-5]. Induction agent, the opioid and the muscle relaxant used should have faster onset and shorter duration of action. Desflurane has been attributed to have a faster offset of action due to its low blood gas partition coefficient 0.42 [6]. Its use is associated with a lower incidence of postoperative delirium [7]. Propofol has faster emergence from anesthesia due to its pharmacokinetic properties and has been used for short surgical procedures [8]. Several studies compared the intravenous anesthetics and inhalational anesthetics with conflicting results $[2,8,9]$. Hence, we designed this study using these anesthetic agents with rapid onset and offset of actions using different methods of administration to provide faster emergence and less post-operative cognitive dysfunction in short surgical procedures.

\section{METHODS}

The study was conducted at a tertiary care hospital between February 2015 and May 2017 after approval from the institutional research and human ethics committee. (MGMCRI- PG/2014/120). Of the expected 600 elective short surgical cases, 50 patients were sampled by a computer generated randomization. Subjects between 30 and 60 years of age belonging to ASA 1 and 2 posted for short surgeries with surgical time $<60$ min were included in the study. Patients with a body mass index (BMI) more than 30 , history of alcohol intake, smoking, on anti-psychiatric medication, and those allergic to the general anesthetic were excluded from the study.
After obtaining written informed consent, patients were explained about Mini Mental State Examination (MMSE). Baseline MMSE score was recorded. Patients with score $<23$ were excluded from the study. Patients were advised a fasting period of $6 \mathrm{~h}$ and received Tab. Ranitidine $150 \mathrm{mg}$, Tab. Metoclopramide $10 \mathrm{mg}$ and Tab. Alprazolam $0.5 \mathrm{mg}$ orally the night before and on the morning of surgery.

After shifting to operation theatre patients were intravenously cannulated with $18 \mathrm{G}$ venflon, preloaded with $10 \mathrm{ml} / \mathrm{kg}$ of Hartmann's solution/normal saline, standard basic monitors were connected, and the baseline vitals recorded. Patients received Inj. Midazolam 0.05 mg. $\mathrm{kg}^{-1}$ and Inj. Fentanyl 2 mcg. kg ${ }^{-1}$ intravenously. They were randomized by a sealed envelope technique into two groups $(n=25)$ Group D and Group P.

All the patients received mixture of intravenous lignocaine $1 \mathrm{ml}$ and propofol (NEOROF $®$ - Neon Lab) through target controlled infusion (TCI) pump (Injectomat $®$ TIVA Agilia, Fresenius Kabi) to achieve a plasma site concentration (Cp) of $6 \mathrm{mcg}^{\mathrm{ml}} \mathrm{m}^{-1}$ (Marsh model). After loss of verbal response, appropriate size I GEL was inserted. The correct position of I GEL was confirmed by absent gastric insufflation, bilateral air entry on auscultation, and capnography. The patients were connected to the circle system with a flow rate of $3 \mathrm{~L} / \mathrm{min}\left(\mathrm{N}_{2} \mathrm{O}: \mathrm{O}_{2} 2: 1\right)$.

In Group D patients, propofol was stopped and Desflurane (SUPRANE (B - Baxter) concentration was kept at $6 \%$ to achieve 1 Minimum Aleveolar Concentration. After $10 \mathrm{~min}$, the flow rate was reduced to $1 \mathrm{~L} / \mathrm{min}$ and dial setting was adjusted to maintain End Tidal Desflurane concentration $3 \%$ with $50 \% \mathrm{~N}_{2} \mathrm{O}$. The patients were kept 
spontaneous. In Group P, the maintenance of anesthesia was continued using Propofol Cp 3 mcg.ml- $\mathrm{m}^{-1}$ The flow rate was at $3 \mathrm{~L} / \mathrm{min}\left(\mathrm{N}_{2} \mathrm{O}: \mathrm{O}_{2} 2: 1\right)$ for $10 \mathrm{~min}$ and then $1 \mathrm{~L} / \mathrm{min}\left(50 \% \mathrm{~N}_{2} \mathrm{O}\right)$.

The heart rate (HR), mean blood pressure (BP), and saturation ( $\left.\mathrm{SPO}_{2}\right)$ were recorded at baseline, induction, and during laryngeal mask airway (LMA) insertion for every $5 \mathrm{~min}$. End-tidal $\mathrm{CO}_{2}$, respiratory rate was recorded after LMA insertion every $5 \mathrm{~min}$. Bradycardia and hypotension ( $\leq 20 \%$ from baseline) treated with a decrease in Desflurane dial concentration by $0.5 \%$ in Group D and decrease in Cp of Propofol TCI by 0.5 mcg.ml $^{-1}$ in Group P and then with Inj. Atropine $0.6 \mathrm{mg}$ or Inj. Mephentermine $6 \mathrm{mg}$ titrated, respectively. Tachycardia and hypertension $(\geq 20 \%$ baseline) were treated with a bolus of Inj. Fentanyl $10 \mathrm{mcg}$, increase in Desflurane dial concentration by $0.5 \%$ in Group D and increase in Cp of Propofol by $0.5 \mathrm{mcg} / \mathrm{ml}$ in Group P.

In Groups $\mathrm{D}$ and $\mathrm{P}$, the agents were stopped at the end of surgery along with $\mathrm{N}_{2} \mathrm{O}$. This was noted as time 0 . The flow rate of $\mathrm{O}_{2}$ was increased to $6 \mathrm{~L} / \mathrm{min}$. Awakening time was defined as the time taken from 0 to eye open, hand grip, LMA removal and state name to call every min. LMA was removed after assessing hand grip. These were noted by a different observer. The patient was shifted to post anesthesia care unit (PACU) and the time recorded as Time 0 PACU admission. The modified Aldrete score was carried for the readiness to discharge. The MMSE score was recorded at $1 \mathrm{~h}, 6 \mathrm{~h}$, and $24 \mathrm{~h}$ postoperatively. Post-operative cognitive dysfunction was defined as a decrease in score of 2 from the baseline. Postoperatively, shivering and pain were treated with Inj. Tramadol $1 \mathrm{mg} . \mathrm{kg}^{-1}$, nausea and vomiting were treated with Inj. Ondansetron $4 \mathrm{mg}$.

\section{Sample size calculation}

Based on the previous studies where standard deviation of 3.64 to demonstrate a mean difference of $3.5 \mathrm{~min}$ time to response to call with a power at 0.8 and alpha at 0.05 .

$\mathrm{n}=\left(2\left(\mathrm{Z}_{\alpha}+\mathrm{Z}_{1-\beta}\right)^{2 \sigma 2}\right) / \Delta^{2}$

$\mathrm{n}$ is the required sample size, $\mathrm{Z} \alpha$ is 1.96 and $\mathrm{Z} 1-\beta$ is $0.8416, \sigma$ is standard deviation, and $\Delta$ is the mean difference in time. 25 in each group were taken as the sample size.

\section{Statistical analysis}

Statistical analysis was carried out using SPSS version 16.0 (IBM SPSS, US) software, Regression Modules installed. Age, weight, height, BMI, duration of surgery, time to eye open, time to squeeze hand, time to removal of LMA, time to state name, time from removal of LMA to PACU admission, Modified Aldrete score, and MMSE score which followed normal distribution were compared using independent sample t-test. Mean BP and MMSE score were compared using paired sample t-test to find statistical difference within the groups.

\section{Consort diagram}

The study was completed in 50 patients undergoing elective minor surgical procedure.

\section{RESULTS}

The demographic data were comparable between the two groups (Table 1). The HR was recorded at Baseline, Induction, LMA insertion and every 5 min thereafter. There was no significant difference in HR between the groups (Fig. 1). The mean BP was recorded at Baseline, Induction, LMA insertion every 5 min thereafter. There was a fall in BP after induction in both the group $\left({ }^{* * *} \mathrm{p}=0.000\right)$. There was no significant difference in BP between the groups (Fig. 2). The $\mathrm{EtCO}_{2}$ was recorded at Induction, LMA insertion and every 5 min thereafter. $\mathrm{EtCO}_{2}$ was maintained between 30 and $35 \mathrm{mmHg}$. There was no significant difference between the groups.

The awakening time was noted from time of stopping of agent to eye open, squeeze hand, LMA removal and state name. The mean awakening time was faster in the Desflurane group when compared to propofol group and found to be statistically significant $\left({ }^{* * *} \mathrm{p}=0.000\right)$. The mean time to eye open, squeeze hand, removal of LMA, state name in the propofol and Desflurane group was $10.41 \pm 2.31$ min versus $06.21 \pm 01.42 \mathrm{~min}, 11.38 \pm 2.41 \mathrm{~min}$ versus $7.42 \pm 2.03 \mathrm{~min}, 12.32 \pm 2.50$ versus $8.18 \pm 2.28 \mathrm{~min}$, and14.12 $\pm 3.37 \mathrm{~min}$ versus $10.18 \pm 2.23 \mathrm{~min}$, respectively (Fig. 3).

The time from stopping the agent and removal of LMA to PACU admission was noted. The mean time from stopping the agent to PACU admission $\left({ }^{* * *} \mathrm{p}=0.000\right)$ and from removal of LMA to PACU admission $(\mathrm{p}=0.039)$ was faster in the Desflurane group (Fig. 4). All the patients were found to be eligible to be discharged from PACU at the time of admission by Modified Aldrete Score. There were no difference between the group $(\mathrm{p}=0.365)$. MMSE taken preoperatively, postoperatively $1 \mathrm{~h}, 6 \mathrm{~h}$, and $24 \mathrm{~h}$ showed no difference between the groups. Within the groups the MMSE scores increased from the baseline post $6 \mathrm{~h}$ and $24 \mathrm{~h}$ which were statistically significant in both Groups $\left({ }^{* *} \mathrm{p}=0.000\right)$ but clinically insignificant (Fig. 5).

\section{DISCUSSION}

There are limited studies comparing the awakening time and recovery of cognitive function between Desflurane and Propofol due to the unavailability of specialized Desflurane vaporizer in many centers in India. In our study we have used the two rapid acting agents which offer rapid emergence, Propofol and Desflurane.

We have excluded patients with a BMI more than 30 and BMI was comparable between the two groups. This is of importance because Propofol is lipid soluble drug and has different pharmacokinetic properties than Desflurane. Juvin et al. [10] found that Propofol delayed the recovery in morbidly obese patients. Servin et al. [11] found that elimination of propofol did not change from obese patients to lean patients. Ingrande et al. [12] concluded that the dose of propofol should be scaled according to the lean body weight.

Studies conducted on Desflurane on the duration of surgeries concluded that the length of surgery has no influence on the recovery profile of Desflurane $[13,14]$. However, two studies conducted on propofol concluded that the length of surgery might have an influence on the pharmacokinetics of propofol and may delay recovery $[15,16]$. To avoid this bias, we had selected only surgeries which needed anesthesia of $<60 \mathrm{~min}$.

In our study, we found that the HR and mean BP were comparable between the groups. Mahli et al. [17] found that there was significant increase in the HR and mean BP in the Propofol group when compared

Table 1: Demographic data

\begin{tabular}{llll}
\hline Parameter & $\begin{array}{l}\text { Group 1, Propofol-N20 } \\
\text { (mean [SD]) }\end{array}$ & $\begin{array}{l}\text { Group 2, Desflurane-N20 } \\
\text { (mean [SD]) }\end{array}$ \\
\hline Age & $41.8(6.12)$ & $41.88(9.76)$ & $57.8(7.36)$ \\
Weigh & $56.8(6.44)$ & $1.58(0.04)$ & 0.97 \\
Height & $1.57(0.03)$ & $23.0(3.16)$ & 0.58 \\
BMI & $22.9(2.15)$ & $32.6(11.09)$ & 0.25 \\
Duration of surgery & $30.6(10.44)$ & & 0.85 \\
\hline
\end{tabular}

BMI: Body mass index 


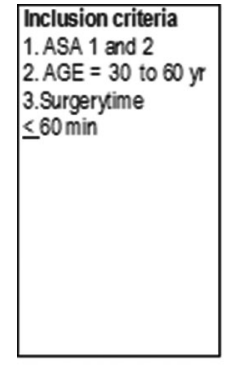

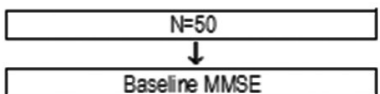

$\downarrow$

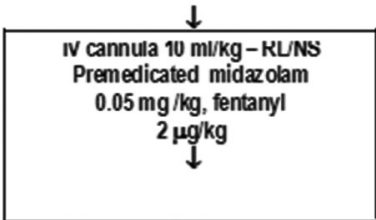

Sealed envelope technique

\begin{tabular}{l} 
Exclusion criteria \\
1. MMS SCORE < 23 \\
2. Smoker \\
3. Pregnant patient \\
4. BMI >30 \\
5. Recent Wo alcohd intake \\
6. Drug abuse patient on \\
psychiatric medications \\
7. Malignant disease \\
8. Chronic pain condition \\
9.Allergic to the general \\
anaesthetic used \\
10. Patient refusal \\
\hline
\end{tabular}

DESFLURANE
GD (n=25)

$\downarrow$

Induction Propofol TCI

Cp $6.0 \mu \mathrm{g} / \mathrm{ml}$ (marsh model) after

loss of verbal respons appropriate size LMA (igel) inserted

Group D patients
Propofol (NEOROF (2) - Neon Lab) was stopped.
Desflurane (SUPRANE Q - Baxter) concentration $6 \%$ flow rate
of 3 Umin $\left(\mathrm{N}_{2} \mathrm{O}_{2} \mathrm{O}_{2} 2: 1\right)$
After achieving 1 MAC fow rate reduced
$t_{0} 1 \mathrm{Lmin}$ and Desflurane dial setting adjusted to $3 \% \mathrm{Et}$ ( $50 \%$
$\left.\mathrm{~N}_{2} \mathrm{O}\right)$

INTRAOPERATNE HR, NIPB, MAP, SPO2, ETCO2, RREVERY 5 MIN TILL END OF SURGERY

Propofol (NEOROF (B) - Neon Lab) was continued.

Propofol plasma conc. (Cp) reduced to $3 \mu \mathrm{g} / \mathrm{ml}$, flow rate of $31 \mathrm{~min}\left(\mathrm{~N}_{2} \mathrm{O}: \mathrm{O}_{2} 2.1\right)$

Ater $10 \mathrm{~min}$ flow rate reduced to $1 \mathrm{~L} / \mathrm{min}$ for rest of

the procedure $\left(50 \% \mathrm{~N}_{2} \mathrm{O}\right)$

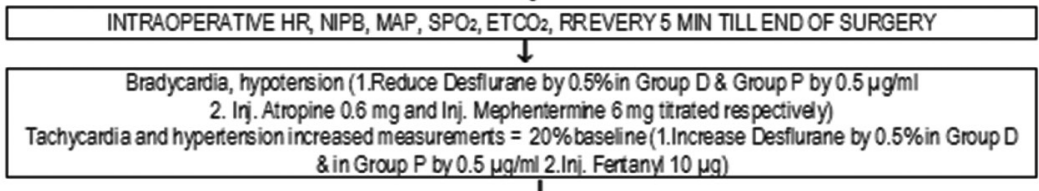
\& in Group P by $0.5 \mu \mathrm{g} / \mathrm{ml}$ 2.Inj. Fertany $10 \mu \mathrm{g})$

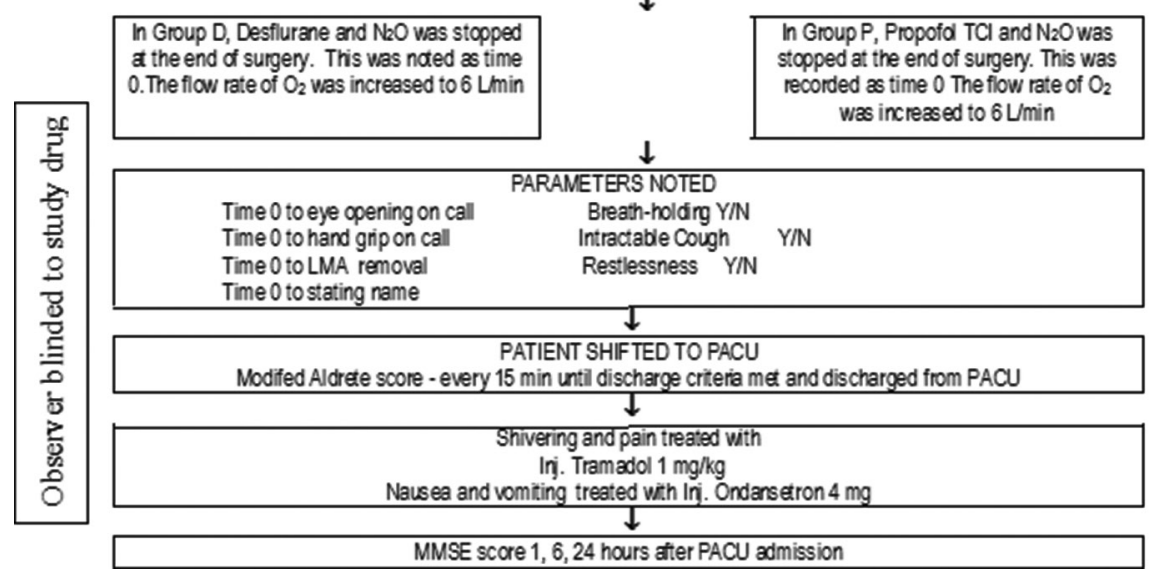

with the Desflurane group. The increase in HR was because the patients had not received any premedication in their study.

The recovery from the state of anesthesia can be divided as Immediate, Intermediate and Long term. Immediate recovery refers to the patient who awakens from anesthesia and has gained his protective airway and motor reflex. The time to eye open, state name and extubating have been used as a measure to assess the immediate recovery. Intermediate recovery refers to the patient who regains his coordination ability and is not dizzy. In day care surgeries patient may be considered for discharge with a responsible attendant at this stage. Post-operative Aldrete score, post-operative quality recovery scale has been used to measure the intermediate recovery. Longterm recovery refers to the patient who has attained full recovery and is able to take care of his own activities. Post-operative cognitive function tests and telephonic questionnaire have been used. The long-term recovery may be delayed postoperatively to several weeks or months [18].
Our study showed faster awakening time with Desflurane than Propofol which is similar to previously published literature $[1,2,4,10,19,20]$. However, a study conducted by Larsen et al. [8] where only propofol group patients received Remifentanil, showed faster awakening time in Propofol when compared to Desflurane $(3.7 \pm 2.6 \mathrm{~min}$ vs. $6.2 \pm 2.6 \mathrm{~min})$. This could be due to Remifentanil pharmacokinetics. Faster awakening time lowers the risk of aspiration [21]. Our study found no incidence of breath holding, intractable coughing or restlessness during emergence similar to the study conducted by Lebenbom-Mansour et al. [4].

Modified Aldrete scoring system was used in our study. The patients were ready to be discharged from PACU at the time of admission and there were no difference between the groups. Similar results have been shown in other studies [1-3,19,22]. Juvin et al. [10] showed more Desflurane patients could be discharged earlier from the PACU compared with the Propofol group in morbidly obese patients. The lipid soluble nature of Propofol in obese individuals may explain this difference. 


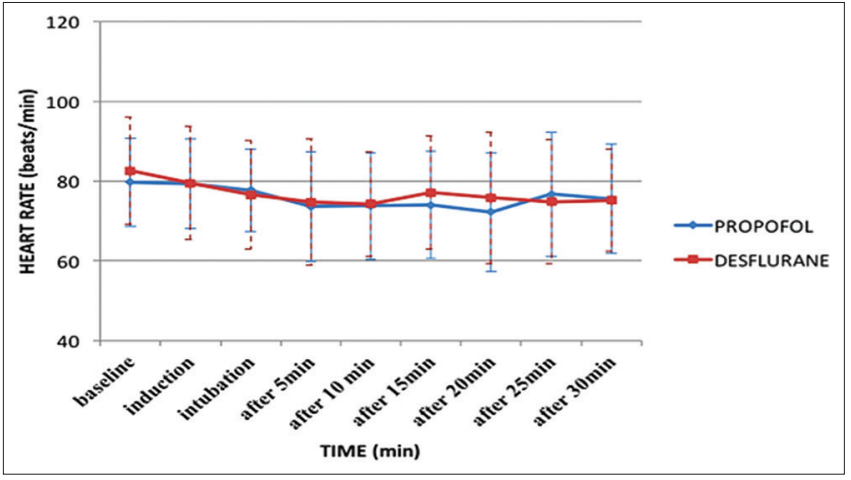

Fig. 1: Trend of heart rate change

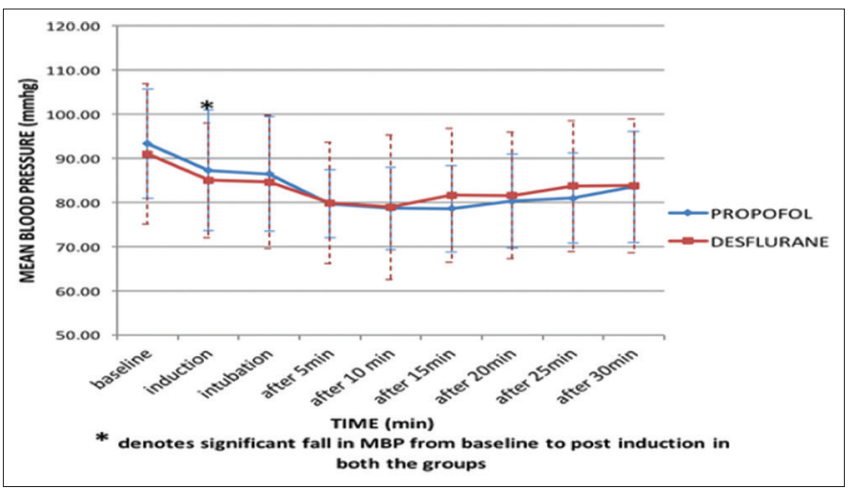

Fig. 2: Trend of mean blood pressure change

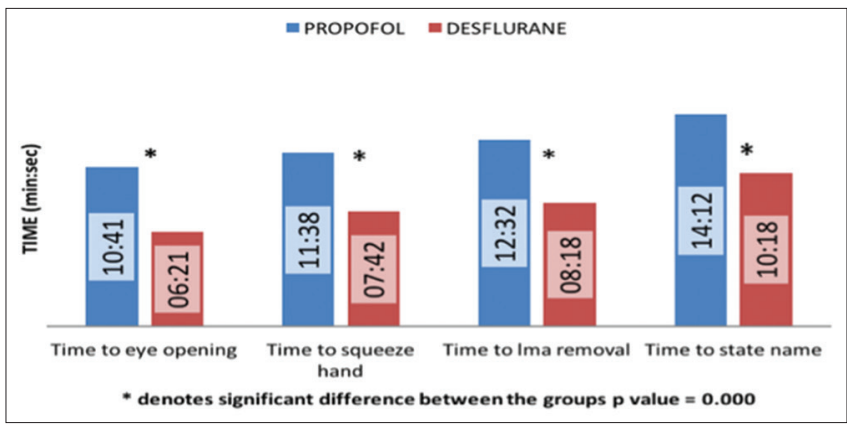

Fig. 3: Mean awakening time between the groups

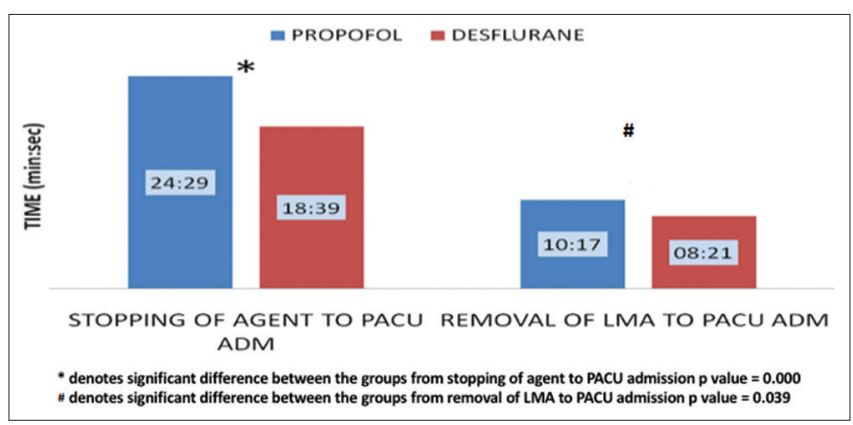

Fig. 4: Time to post-anesthesia care unit admission

After discontinuation of the agent and removal of LMA, the patients spent considerable time in the operation theater waiting to state their names which has led to late shifting of patients to the PACU. Hence, we could not achieve any difference in Alderte score. To avoid this bias, Mahmoud et al. [23] shifted the patient to the PACU with the LMA in situ.

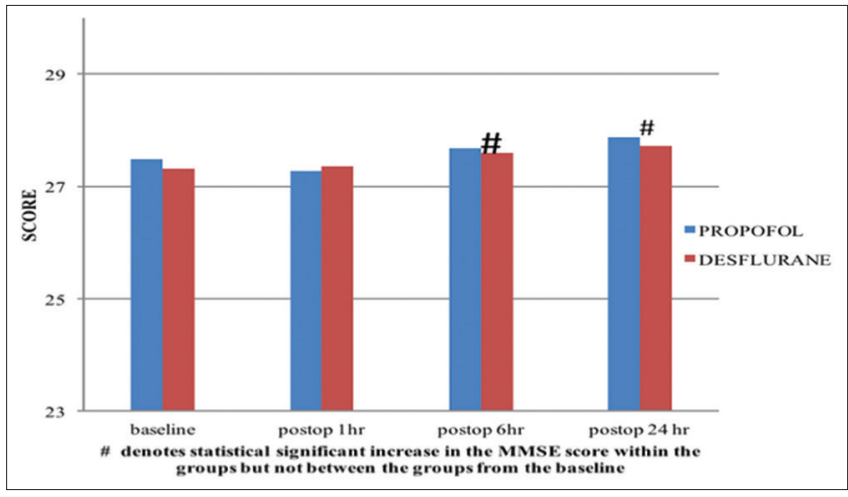

Fig. 5: Mini Mental State Examination score between the groups

MMSE Score was used to identify postoperative cognitive function. A score $<2$ from the baseline was considered to have mild cognitive defect. In our study, MMSE were comparable between the groups. In the propofol group, we have 3 out of 25 patients who had a decline of score $<2$ from baseline when taken $1 \mathrm{~h}$ post-operative indicating these patients have a mild cognitive defect. However, we did not have any patients in the Desflurane group who had a fall in score of 2. However, when comparing the mean Mini Mental score from the baseline between Propofol and the Desflurane we did not achieve any statistical significance. Our study showed 8 out of 25 and 7 out of 25 patients had an improvement in the score when taken from the baseline in Propofol and Desflurane group, respectively. This phenomenon has been addressed in a study by Galasko et al. [24] on Alzheimer's patient. This was due to the practice effect where the patient learnt the answers to the question when questioned repetitively.

\section{Limitations of the study}

After discontinuation of the agent and removal of LMA, the patients spent considerable time in the operation theatre waiting to state their names which has led to late shifting of patients to the PACU. Hence, we could not achieve any difference in Aldrete score. Both these drugs are relatively new and used in day care surgeries. Desflurane is by far the latest inhalational agent and its used and compared with established drug like Propofol.

\section{CONCLUSION}

We conclude that Desflurane has an advantage in providing brief awakening time than Propofol in short surgical procedure. However, recovery of cognitive function was comparable between the two groups. There were no adverse side effects during emergence in both the groups.

\section{AUTHORS CONTRIBUTION}

(1) Fernaz Basha: Data collection, Analysis. Parthasarathy S: Writing.

(2) Antony John Charles S: Writing in part and Communication.

(3) Ravishankar M: Concept, Ideas, Design. (4) Hemanth Kumar VR: Analysis in part.

\section{CONFLICT OF INTEREST}

Nil to all authors.

\section{FINANCIAL SUPPORT}

Nil.

\section{ETHICAL APPROVAL}

Human - YES - Date and number mentioned in the manuscript.

\section{REFERENCES}

1. Tang J, White PF, Wender RH, Naruse R, Kariger R, Sloninsky A, et al . Fast-track office-based anesthesia: A comparison of propofol versus 
desflurane with antiemetic prophylaxis in spontaneously breathing patients. Anesth Analg 2001;92:95-9.

2. Bailey CR, Ahuja M, Bartholomew K, Bew S, Forbes L, Lipp A, et al. Guidelines for day-case surgery 2019. Anaesthesia 2019;74:778-92.

3. Ashworth J, Smith I. Comparison of desflurane with isoflurane or propofol in spontaneously breathing ambulatory patients. Anesth Analg 1998;87:312-8.

4. Lebenbom-Mansour MH, Pandit SK, Kothary SP, Randel GI, Levy L. Desflurane versus propofol anesthesia: A comparative analysis in outpatients. Anesth Analg 1993;76:936-41.

5. Graham SG, Aitkenhead AR. A comparison between propofol and desflurane anaesthesia for minor gynaecological laparoscopic surgery. Anaesthesia 1993;48:471-5.

6. Ebert JE, Lindenbaum. Inhaled Anaesthetics. In: Barash G, editor. Clinical Anesthesia. $7^{\text {th }}$ ed. New Delhi: Wolters Kluwer; 2013. p. 452.

7. Chen G, Zhou Y, Shi Q, Zhou H. Comparison of early recovery and cognitive function after desflurane and sevoflurane anaesthesia in elderly patients: A meta-analysis of randomized controlled trials. J Int Med Res 2015;43:619-28.

8. Larsen B, Seitz A, Larsen R. Recovery of cognitive function after remifentanil-propofol anesthesia: A comparison with desflurane and sevoflurane anesthesia. Anesth Analg 2000;90:168-74.

9. Wrigley SR, Fairfield JE, Jones RM, Black AE. Induction and recovery characteristics of desflurane in day case patients: A comparison with propofol. Anaesthesia 1991;46:615-22.

10. Juvin P, Vadam C, Malek L, Dupont H, Marmuse JP, Desmonts JM. Postoperative recovery after desflurane, propofol, or isoflurane anesthesia among morbidly obese patients: A prospective, randomized study. Anesth Analg 2000;91:714-9.

11. Servin F, Farinotti R, Haberer JP, Desmonts JM. Propofol infusion for maintenance of anesthesia in morbidly obese patients receiving nitrous oxide a clinical and pharmacokinetic study. J Am Soc Anesthesiol 1993;78:657-65.

12. Ingrande J, Brodsky JB, Lemmens HJM. Lean body weight scalar for the anesthetic induction dose of propofol in morbidly obese subjects. Anesth Analg. 2011;113:57-62.

13. Lin TC, Lu CC, Hsu CH, Wu GJ, Lee MS, Ho ST. Duration effect of desflurane anesthesia and its awakening time and arterial concentration in gynecologic patients. Clinics 2013;68:1305-11.
14. Eger EI, Gong D, Koblin DD, Bowland T, Ionescu P, Laster MJ, et al. The effect of anesthetic duration on kinetic and recovery characteristics of desflurane versus sevoflurane, and on the kinetic characteristics of compound A, in volunteers. Anesth Analg 1998;86:414-21.

15. Gindre B, Baulieux D. Correlation of age-recovery time and the length of procedure-recovery time with propofol. Ann Fr Anesth Reanim 1989;8:78

16. Pascoe PJ, Ilkiw JE, Frischmeyer KJ. The effect of the uration of propofol administration on recovery from anesthesia in cats. Vet Anaesth Analg 2006;33:2-7.

17. Mahli A, Coskun D, Karaca GI, Akcali DT, Karabiyik L, Karadenizli Y. Target-controlled infusion of remifentanil with propofol or desflurane under bispectral index guidance: Quality of anesthesia and recovery profile. J Res Med Sci 2011;16:611-20.

18. Rasmussen LS. Postoperative cognitive dysfunction: Incidence and prevention. Best Pract Res Clin Anaesthesiol 2006;20:315-30.

19. Röhm KD, Piper SN, Suttner S, Schuler S, Boldt J. Early recovery, cognitive function and costs of a desflurane inhalational vs. a total intravenous anaesthesia regimen in long-term surgery: Costs and cognitive function after desflurane vs. TIVA. Acta Anaesthesiol Scand 2006;50:14-8

20. Harrison C, Remoundos DD, Harvey KL, Stoker GV, MacLean G, Adwani $\mathrm{A}$, et al. Increasing the incidence of drain-free day-case mastectomies with the use of a fibrin tissue sealant; data from a single surgical center in the United Kingdom. Breast J 2019;25:1090-6.

21. Juvin P, Servin F, Giraud O, Desmonts JM. Emergence of elderly patients from prolonged desflurane, isoflurane, or propofol anesthesia. Anesth Analg 1997;85:647-51.

22. Rapp SE, Conahan TJ, Pavlin DJ, Levy WJ, Hautman B, Lecky J, et al. Comparison of desflurane with propofol in outpatients undergoing peripheral orthopedic surgery. Anesth Analg 1992;75:572-9.

23. Mahmoud NA, Rose DJ, Laurence AS. Desflurane or sevoflurane for gynaecological day-case anaesthesia with spontaneous respiration? Anaesthesia 2001;56:171-4.

24. Galasko D, Abramson I, Corey-Bloom J, Thal LJ. Repeated exposure to the mini-mental state examination and the information-memoryconcentration test results in a practice effect in Alzheimer's disease. Neurology 1993;43:1559-63. 